\title{
WINDBREAKS FOR PLOVERS
}

JIM WEDGWOOD, 610 Leslie Avenue, Saskatoon, Saskatchewan. S7H $2 Z 2$

Radisson Lake was low in the fall of 1988, and a stony mud flat had become exposed on its west side. While walking towards this shore on 1 October, I saw in the distance a gray lump beside a stone, then more lumps, each beside a stone. Closer, the lumps became Black-bellied Plovers. The day having turned very windy, the birds were using the stones as windbreaks.

Nineteen plovers, each in the lee of a stone, were hunkered down out of the wind. They had selected stones 30 to 45 $\mathrm{cm}$ high, bypassing lower ones, but also avoiding higher boulders (predator fear?). The chosen stones were within $3 \mathrm{~m}$ of the water. All stones used had tops sloping up away from the wind and steep, downwind sides, that is, those making better windbreaks.

No plover was against or touching a stone. Instead, the bird was 15 to $30 \mathrm{~cm}$ away; and the higher the stone, the greater the distance. First, through choice of a stone with an optimal shape, then by positioning itself in relation to the stor height, the birds demonstrated a $k r$ sensitivity to air currents, locating the selves where the wind was minimum. circulation pattern downwind fron stone would be similar to that on the side of a snow fence (maximum sn depth, i.e. minimum air currents, occ not at the fence but rather a distance $f_{c}$, it, the space increasing with height of fence.)

The birds faced randomly, not ne sarily into the wind, an indication of effectiveness of the stones as wi spoilers. A further demonstration was birds' obvious reluctance to move $\mathrm{w}$ I neared them. Peter Matthiessen, ofthe great writers on shorebirds, ca the "the birds of the wind." " That day! displayed another sense of the wind.

STOUT, G.D., PETER MATTHIESS A.V. CLEM and R.S. PALMER. 1! Shorebirds of North America. Viking Pr ; $270 \mathrm{pp}$.

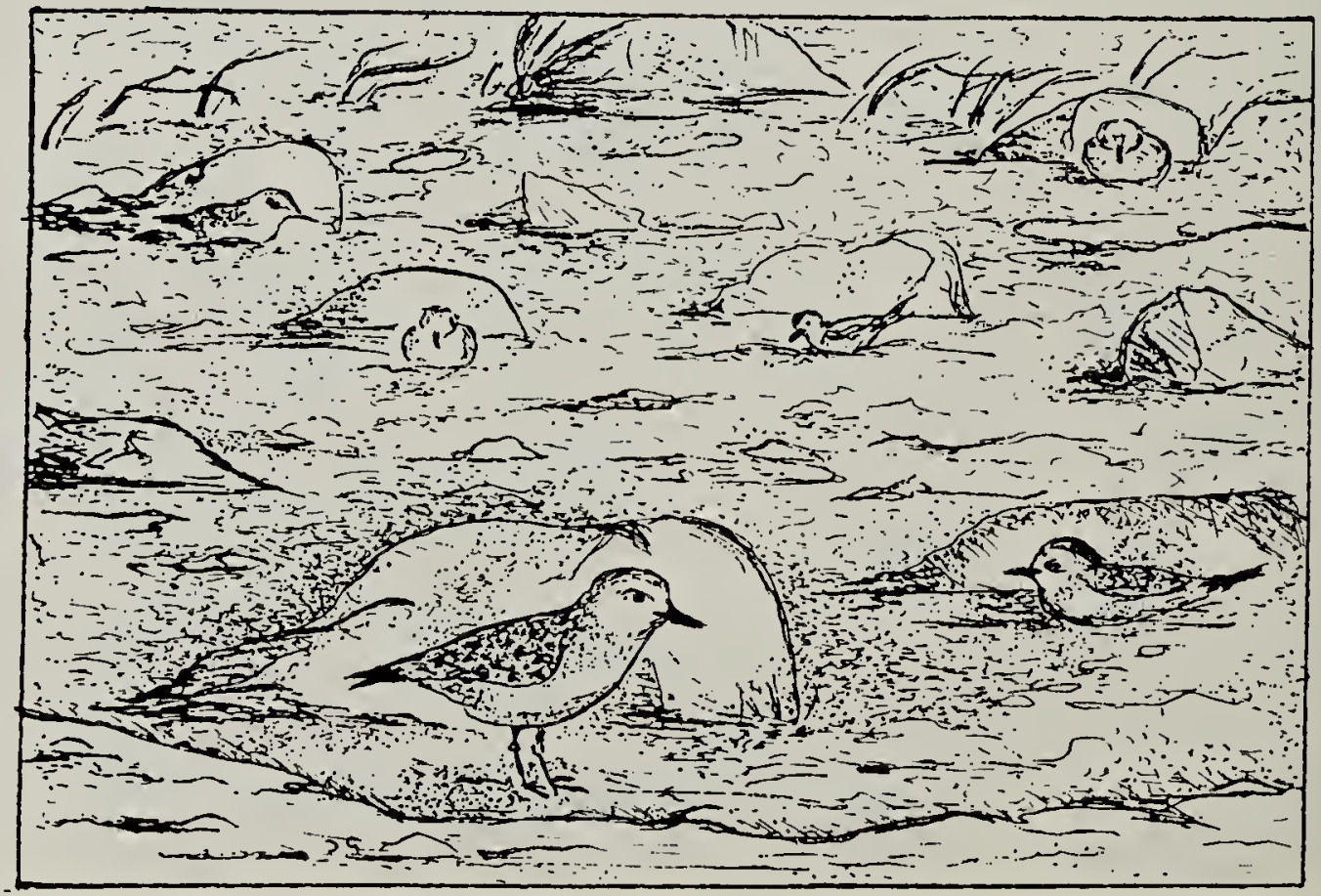

Sketch by Pern Cordery 